\title{
SOBRE AS ETNOCRACIAS DAS AJUDAS HUMANITÁRIAS NO LÍBANO
}

\author{
Ethnocracies of care and humanitarianism in Lebanon
}

Estella Carpi*

\begin{abstract}
Resumo. Neste artigo, discuto a tendência do sistema humanitário de fornecer serviços às pessoas necessitadas em áreas afetadas pela crise baseandose na nacionalidade. Através de dados coletados em pesquisas de campo com refugiados sírios, iraquianos, sudaneses e palestinos realizadas entre os anos 2011 e 2019 no Líbano, mostrarei como a hospitalidade pode ser empregada tanto como prática quanto como discurso. Neste último caso, explicarei como isso pode se transformar, de maneira problemática, em uma força de "etnização" na prestação de ajuda humanitária. Como resultado, de um uso conservador do discurso da hospitalidade, apresentarei o conceito de "humanitarismo compensatório" que atende aos habitantes locais como uma consequência da presença de refugiados. Contra esse pano de fundo, finalmente mostrarei como o sistema humanitário atual está longe de ser intergrupal, apesar de seus esforços para tornar os programas nacionalmente mistos. Na verdade, o humanitarismo simplesmente propõe programas mistos para, presumivelmente, dissipar as tensões intergrupais, revelando, portanto, uma neo-etnização das ajudas.
\end{abstract}

Palavras-chave: etnização; humanitarismo; refugiados sírios; Líbano; deslocamento.

\begin{abstract}
In this article, I discuss the tendency of the humanitarian system in areas affected by crisis to provide services to people in need on a national basis, by using Lebanon as a case study. Through the research I conducted with Syrian, Iraqi, Sudanese and Palestinian refugees between 2011 and 2019 in Lebanon, I will illustrate, first, how hospitality can be employed both as a practice and as a discourse. In the latter case, I will explain how it can problematically turn into an "ethnicization" force in humanitarian aid provision. As a result of a conservative use of the hospitality discourse, second, I will introduce the concept of "compensatory humanitarianism" that caters for the locals as a consequence of the refugee presence. Against this backdrop, I will finally show how the current humanitarian system is far from being inter-group despite its efforts to make programs nationally mixed. Indeed, it simply proposes mixed programs to presumably dissipate inter-group tensions, therefore revealing an actual neo-ethnicization of care.
\end{abstract}

Keywords: ethnicization; humanitarianism; Lebanon; displacement.

Safer Edge. London, United Kingdom. Email: estella.carpi@gmail.com. Orcid: https://orcid. org/0000-0003-4537-0294. 


\section{Introdução ${ }^{1}$}

Neste artigo, contribuo para a compreensão de como a assistência humanitária moderna e contemporânea, como fenômeno do colonialismo tardio, tem marcado e construído identidades raciais e nacionais e tem determinado a formação de grupos sociais nas áreas de intervenção. Em maiores detalhes, discutirei a tendência do sistema humanitário de fornecer serviços às pessoas necessitadas nas áreas afetadas pela crise baseando-se na nacionalidade; uma tendência muito comum no Líbano.

Ao longo dos meus anos de pesquisa sobre deslocamento humano no Líbano (por exemplo CARPI, 2018, 2020a, 2020b), especialmente nas periferias da capital Beirute e no norte do país, observei como libaneses, palestinos, iraquianos e sírios deslocados responderam a um tipo de tendência logística que chamo de "etnização" das necessidades e dos serviços. Para explicar como essa tendência se manifesta na experiência humanitária, fiz um esforço sociológico para pensar nos refugiados que conheci para além de suas histórias individuais. Suspender narrativas individualizadas ajuda a capturar como os grupos sociais se entendem dentro do Líbano e em suas relações transnacionais; como eles se relacionam e qual é sua experiência coletiva em relação à fornecimento de ajuda. Falar sobre grupos em vez de indivíduos não remove as experiências singulares das pessoas, mas lança luz sobre sua interpretação social acerca de padrões recorrentes orientados para o grupo. Novas ondas de migrações induzidas por crises podem matizar, mudar radicalmente ou se fundir em respostas sociais à crise.

Entre 2011 e 2019², através de observação etnográfica e entrevistas com praticantes das Nações Unidas e das ONGs, residentes locais, migrantes e refugiados, examinei as consequências sociais de um sistema etnocrático indiretamente estabelecido pelo fornecimento de ajuda a cidadãos locais vulneráveis que residem nos subúrbios ao sul de Beirute (ad-Dahiye al-Janubiye) junto com grupos de refugiados iraquianos e sudaneses mais antigos que habitam os subúrbios, e refugiados sírios que se mudaram, depois de 2011, para Akkar, uma região historicamente carente do norte do Líbano. A maneira como as agências humanitárias abordaram áreas demograficamente mistas levou-me a acreditar que as agências veem a etnia como um marcador político de pertencimento e identidade nacional (Smith, 1981), que, neste caso, marca as fronteiras entre libaneses, sírios, palestinos, sudaneses e iraquianos. A este respeito, as agências humanitárias abordam diferentes grupos demográficos e religiosos no Líbano como diferentes etnias devido à sua história

1 Agradeço à Professora Patrícia Prado da Pontifícia Universidade Católica de Minas Gerais (PUC Minas) por sua inestimável ajuda na edição do artigo. Esta publicação não teria sido possível em português sem ela.

2 Antes, no âmbito dos meus estudos de doutoramento (2011-2015), e a partir de 2017 no contexto do projeto "Southern Responses to Displacement from Syria: Views from Lebanon, Jordan and Turkey" na University College London (número do contrato de concessão do European Research Council: 775411). 
política peculiar em uma multiplicidade de elementos culturais, confessionais e linguísticos.

Embora me distancie de aderir a concepções de etnias orientadas pela nacionalidade, penso que o termo "etnicização" particularmente seja adequado para refletir como o humanitarismo opera na prática. Isso inclui lidar com grupos demográficos vizinhos (predominantemente árabes) como se fossem diferentes etnias que precisam se reconciliar, enquanto desconsidera continuidades e diferenças entre suas classes sociais e origens políticas. Isso também acontece porque alguns grupos de refugiados tendem a viver nas mesmas áreas, principalmente iraquianos e sudaneses. Contudo, os refugiados urbanos sírios estabelecem uma demografia diferente nas cidades devido ao seu número maior.

Ao contrário da análise de Haqqi Bahram da política de pertencimento dos refugiados curdos sírios e seu deslocamento intra-étnico (2020), encontrei muito poucos refugiados não árabes e pessoas deslocadas internamente (PDI) em meus locais de pesquisa. Como resultado, estou motivada a investigar como as práticas humanitárias criam e gerenciam "comunidades étnicas" em uma tentativa de construir coesão social e estabilidade dentro da sociedade receptora e, mais importante para os atores globais, para preservar uma conveniente ordem social e política. Usando a etnização como lente de interpretação, investiguei anteriormente (2018) como os refugiados iraquianos e sudaneses se entendiam vis-à-vis as estruturas de gestão de assistência durante a guerra de julho 2006 entre o Líbano e Israel ${ }^{3}$ e em resposta ao clima político local e internacional. Apesar de suas experiências serem todas peculiares, o padrão geral de etnicização definiu, para mim, como os iraquianos e sudaneses tornaram-se grupos sociais ainda mais distintos no Líbano após a guerra de julho; eles estavam separados da sociedade local, mas também uns dos outros.

No primeiro momento, a maioria das organizações humanitárias - cujos serviços variavam da construção de abrigos à organização de atividades lúdicas para os deslocados - abordavam grupos sociais separadamente, acreditando que o programa humanitário deveria ser seguro e deveria refletir as histórias relacionais locais entre os grupos, para que o atrito não fosse gerado. No entanto, a partir do final de 2014, após a primeira versão do Plano de Resposta à Crise do Líbano (PRCL), o programa humanitário passou a abordar todos os grupos sociais em conjunto, promovendo o que, neste contexto, pode ser denominado de projetos "interétnicos". Desde o resultado do meu trabalho de campo de doutorado entre 2011 e 2013, o humanitarismo abraçou uma nova etnicização das ajudas, presumindo que as tensões e a violência ocorrem predominantemente em regiões nacionalmente híbridas e, com isso, consolidando a ideia de uma ordem racializada primordial. Depois de alguns anos desde a chegada dos refugiados sírios ao Líbano,

\footnotetext{
3 Nesse conflito, Israel atacou as áreas libanesas governadas pelo principal partido xiita libanês, o Hezbollah. Isso também é chamado "guerra de 33 dias", onde os ataques da aviação israelense causaram mais de 1.000 vítimas, especialmente no sul do Líbano.
} 
o programa humanitário foi redesenhado para a inclusão e para que os grupos sociais se misturassem como se não tivesse uma história relacional intergrupal anterior. Meu argumento é que a desmontagem da etnização de necessidades e de serviços foi praticamente substituído por uma nova etnocracia das ajudas - por assim dizer, um sistema ainda baseado na pertença etnizada - que, por sua vez, possui programas inclusivos nacionalmente.

Em suma, os grupos de refugiados são administrados, controlados e assistidos em diferentes espaços que são ainda compartimentados por regimes humanitários e de bem estar social. A logística de como diferentes grupos de refugiados são assistidos acaba fortalecendo uma modalidade de provisão de ajuda orientada para a etnia (com "étnico" sendo mal interpretado como um conflito inato). Neste artigo, primeiro, vou explicar como a hospitalidade pode ser empregada tanto como prática quanto como discurso. Neste último caso, explicarei como isso pode se transformar, de maneira problemática, em uma força de etnização na prestação de ajuda humanitária. Como resultado de um uso conservador do discurso da hospitalidade, como será evidenciado no decorrer do texto, apresentarei o conceito de "humanitarismo compensatório" que atende os moradores locais à luz da presença dos refugiados. Contra esse pano de fundo, finalmente mostrarei como o sistema humanitário atual está longe de ser intergrupal, apesar de seus esforços para tornar os programas nacionalmente mistos. Na verdade, o humanitarismo simplesmente propõe programas mistos para - presumivelmente - dissipar as tensões, revelando, portanto, uma neo-etnização das ajudas.

\section{A hospitalidade local como força de etnização}

Na última década, estudos sobre governos, bem como grupos de cidadãos, migrantes ou refugiados que fornecem "hospitalidade" a pessoas que fogem da guerra e da violência floresceram (Brun, 2010; Carpi, Senoguz 2018; FiddianQasmiyeh, Qasmiyeh, 2017; Pitt-Rivers, 2012; Rosello, 2002; Shryock, 2004). Da mesma forma, a hospitalidade se tornou a principal estrutura discursiva que capta as múltiplas maneiras pelas quais os moradores libaneses vivem lado a lado com os refugiados sírios em espaços humanitários. O discurso político de hoje sobre hospitalidade ofusca a longa história relacional entre essas populações, bem como a pré-sociologia da presença síria em lugares como o norte do Líbano, onde casamentos mistos eram a norma.

Relatórios de organizações não-governamentais (ONGs) e mídia internacional têm se concentrado cada vez mais em moradores do Líbano, Turquia e Jordânia, que hospedaram seus "visitantes refugiados" e que posteriormente receberam legitimidade internacional como "anfitriões", qualquer que seja sua atitude em relação à chegada de refugiados. Como resultado, a hospitalidade tornou-se um fator chave na etnização ativa das relações entre moradores e refugiados e na construção de descrições antagônicas de fatos sociais que giram em torno de 
"libaneses versus sírios». Além disso, é sensato usar a hospitalidade em um contexto social porque, quando falamos de "anfitriões", reconhecemos eticamente um grupo ou categoria de pessoas diante do outro; até certo ponto, estamos predeterminando papéis sociais.

A hospitalidade no Oriente Médio cumpriu a estratégia do governo local de usar a migração forçada como um instrumento de soft power para moldar as relações entre os estados e obter benefícios internacionais, sendo o acordo UE-Turquia de 2016 o caso mais notável. ${ }^{4}$ Portanto, a cobertura da mídia internacional deu moralidade aos "anfitriões" regionais e sua (in)capacidade material para hospedar e acolher refugiados. Isso é particularmente paradoxal em uma região onde tem uma luta desesperada pela sobrevivência econômica e onde as pessoas têm sido cronicamente negligenciadas desde o mandato francês (1920), o Estado pós-Pacto Nacional (1943) e o Acordo pós-Taef que encerrou a Guerra Civil no Líbano (1990).

Senoguz e eu (2018) refletimos sobre a situação dos refugiados no Líbano e na Turquia, onde os comentários políticos na mídia usaram a hospitalidade para comparar eticamente os países de acolhimento (por exemplo, os estados mais acolhedores versus os menos acolhedores). Discutir a hospitalidade no nível estadual é diferente de discuti-la no nível das pessoas. O esquecimento de que esses dois níveis estão separados abre caminho para uma perigosa intercambialidade entre os níveis microindividual e macropolítico. No entanto, o funcionamento governamental, humanitário e diário da hospitalidade se sobrepõe em certa medida, exercendo uma política assertiva de soberania sobre os refugiados e transmitindo a ideia de Estados-Nação hospitaleiros. Enquanto permanecermos dentro do repertório terminológico de hospitalidade e estados "anfitriões", os refugiados não se tornarão parte integrante do tecido social local.

Nesse sentido, o discurso da hospitalidade, marcando sociedades vizinhas que formavam a mesma entidade política, pode atuar fortemente como uma força de fragmentação social, minando relações anteriores que alguns sírios vinham desenvolvendo com locais em países como Líbano e Turquia antes do êxodo da Síria. Nesse ponto, o discurso da hospitalidade pode ser visto como uma força etnizante que constrói um imaginário historicamente impreciso de sírios contra libaneses. A promoção da virtude política dos Estados anfitriões serve ativamente para separar os cidadãos dos refugiados que, em muitos casos, são na verdade migrantes mais antigos, por exemplo no norte do Líbano, que enfrentam novas dificuldades jurídicas, sociais e econômicas. O discurso da hospitalidade também ofusca ativamente a natureza exploradora que as relações locais-refugiados

\footnotetext{
${ }^{4}$ De acordo com a declaração de cooperação de março de 2016, todas as pessoas que chegam de forma irregular (por exemplo, de barco sem permissão ou passagem oficial) para as ilhas gregas, incluindo os requerentes de asilo, seriam devolvidos à Turquia. Em troca, os Estados-Membros da UE aceitariam um refugiado sírio da Turquia por cada sírio regressado das ilhas. Ver: <https://www. consilium.europa.eu/en/press/press-releases/2016/03/18/eu-turkey-statement/>.
} 
adquirem, uma vez que os locais se tornam incondicionalmente "anfitriões" e os vizinhos se tornam refugiados e, portanto, "hóspedes".

No contexto do norte do Líbano (Akkar), o discurso humanitário se fundiu estrategicamente com o discurso da hospitalidade, inicialmente negligenciando a presença de longa data de trabalhadores sírios no Líbano e a difícil relação política entre os locais e o exército sírio após 29 anos de ocupação (1976-2005). ${ }^{5}$ A hospitalidade e, mais especificamente, a formação humanitária da hospitalidade local, acabou produzindo uma forma localizada de nacionalidade libanesa frente ao novo "Outro Sírio". Ao contrário do discurso oficial do governo, em Akkar, as pessoas locais falam dos cidadãos sírios como refugiados (laji'in) ou simplesmente sírios (suryyin).

$\mathrm{O}$ ato coletivo de produzir outsiders, retratando toda a presença síria como refugiada na região, permitiu aos libaneses de Akkar preservar a ordem. No entanto, retratar indistintamente os sírios como refugiados foi, para mim, também um sinal de proximidade política com os novos refugiados e de oposição ao governo sírio que produziu refugiados perseguindo e colocando em perigo seus cidadãos dentro da Síria. A ausência de uma comunidade síria bem ligada no Líbano, "derretendo-se como açúcar no chá" (Chalcraft, 2009), facilitou a tarefa de representar os refugiados sírios como novos outros. Este processo gradual de "transformar os sírios em novos outros" no Líbano ocorreu como uma forma local eficaz de marcar o território como seu, ou seja, para administrar e controlar "a casa".

Em um cenário geopolítico em que o estado de emergência é oficialmente reconhecido, a salvaguarda da "casa" entra em cena como uma estratégia de autodeterminação local de crise. Isso levou os locais de Akkar a reinventar seu relacionamento com os sírios pré-existentes em resposta à crise anunciada. A outrização dos sírios produziu efeitos na população local desenvolvendo novos significados sociais da fronteira física entre os dois países, a Síria e o Líbano. Eu chamo esse fenômeno de "neo-fronteirização" (neo-borderization em Carpi, 2020b), onde afinidades culturais e sociais e até mesmo laços de parentesco comuns tornaram-se fatores marginais no padrão antagônico sírio-versus-libanês e no imaginário anti-histórico dos "doadores libaneses"-"recebedores sírios".

Em outras palavras, a etnização da relação sírio-libanesa deu origem a novas "paisagens fronteiriças" (Lebuhn, 2013) de inclusão e exclusão nas cidades, segundo as quais os libaneses minaram a presença passada de sírios, destacando o caráter precário do trabalho sírio na região antes da crise. A presença de paisagens fronteiriças enfatiza o fardo contínuo de gerenciar a crise - construída como um evento que atua como um divisor de águas - e de lidar com o crescimento populacional rápido e desregulado. Nesse contexto, o ato local de atribuir novos significados de

5 O exército sírio estabeleceu sua presença no Líbano desde 1976, com o início da guerra civil, até abril de 2005, fim da wikala suriyya, que foi oficialmente justificada como forma de proteção à Síria. 
fragmentação social à fronteira é uma lembrança das relações políticas e econômicas do passado do norte do Líbano (Akkar) com seus vizinhos sírios e um convite para reconhecer as necessidades locais e apoiar a força de trabalho local, tornando a presença do "Outro" temporária. Este foi um convite que as agências humanitárias aceitaram somente depois de se dirigirem exclusivamente aos refugiados, e uma vez que perceberam que a ordem local seria facilmente comprometida se os grupos vulneráveis locais não fossem assistidos junto com os refugiados. A luta desesperada pela sobrevivência econômica no norte do Líbano só surgiu quando a comunidade local não foi mais capaz de absorver os recém-chegados.

\section{A mercantilização da hospitalidade como política da identidade}

Exceto para famílias mistas que hospedavam parentes sírios que tinham escapado da guerra, a hospitalidade, na maioria dos casos, dependia de retornos financeiros por meio de aluguéis de casas pagos em dinheiro por organizações humanitárias aos proprietários libaneses. Outros refugiados, impossibilitados de ter acesso a moradias reformadas e fornecidas por agências, acabaram pagando uma quantia de 50 a 100 dólares por mês aos proprietários libaneses por uma barraca ou um pedaço de terra. Na época, as notícias tendiam a disfarçar esses círculos financeiros que acabaram renovando as relações clássicas entre patronos e clientes em Akkar para que pudessem descrever o governo libanês como hospitaleiro, embora sob tensão.

Enquanto algumas familias libanesas receberam dinheiro de organizações humanitárias para acomodar os recém-chegados sírios em uma base anual temporária, várias famílias libanesas inicialmente argumentaram que decidiram hospedar refugiados sírios em nome de laços de sangue, antigas amizades e favores pessoais. Por exemplo, uma família libanesa em al-'Abdeh, uma aldeia de Akkar, disse que estava hospedando uma família síria de cinco pessoas como um favor pessoal para seu médico de família libanês com mulher síria, com quem eles tinham uma amizade de longa data. Ao longo de 2012, quando havia um pequeno número de ONGs internacionais na região, percebi que algumas famílias locais eram sustentadas financeiramente por redes de pessoas entre o Líbano e a Síria que se esforçaram para apoiar os meios de subsistência da comunidade ou de seus familiares no Líbano.

Os profissinais que atuam nas ONGs internacionais geralmente acreditam que uma crise humanitária de tal escala e duração não pode ser administrada com base nos valores culturais de hospitalidade e responsabilidade moral. Para alguns, fornecer apoio financeiro às famílias locais para que pudessem hospedar refugiados era uma necessidade real. Para outros, a política incentivou a população local a tirar proveito da assistência humanitária, o que não resolveu a crise, mas, ao contrário, tornou a acomodação para refugiados temporária e suas condições de vida ainda mais vulneráveis quando os acordos de um ano entre as famílias locais e ONGs 
terminaram. Sarah, uma profissional que trabalhava para uma ONG internacional na aldeia de Qobaiyat (Akkar), argumentou:6 "Não acho que tenha sido uma boa ideia pagar famílias para hospedar sírios. Nós os tornamos dependentes de pessoas que não são independentes, e é apenas um acordo de um ano. O que eles vão fazer depois? O que mudamos ao fazer isso?" Em outras palavras, a cultura da hospitalidade foi financiada e "comercializada" por meio da política humanitária oficial, enquanto a crise, paradoxalmente, se tornou sustentável.

No início de 2013, as ONGs internacionais lideradas pelo "Norte Global" e as ONGs regionais, como as financiadas pelo Golfo Pérsico, adotaram esta política realizando pagamentos diretos aos proprietários libaneses ou fornecendo um subsídio de subsistência para as famílias libanesas anfitriãs e trabalhando em reparações de casas para melhorar os abrigos dos refugiados.

Alguns residentes acabaram alugando pequenos terrenos privados para sobreviver em uma região onde as relações patrono-cliente ainda determinavam a situação econômica do indivíduo. Zena, nascida e criada na aldeia de al-Bahsa, era a dona da barraca de Amal. Ela era dona de uma pequena vila ao lado do terreno para onde a família de Amal se mudou. Em nossas conversas, ela frequentemente enfatizava sua situação financeira em deterioração e teve que retirar seus filhos da escola particular, pois tinha se tornado inacessível: "Por muito tempo, tivemos este terreno em frente de casa, e agora nós alugamos. O que mais podemos fazer sem emprego e sem uma forma de expatriação?"7

Em realidade, alguns dos residentes de Akkar fingiram ser refugiados para perseguir seus desejos legítimos de migração; 17 deles compraram passaportes sírios falsos para que pudessem ser enviados para a costa australiana, mas acabaram se afogando. ${ }^{8}$ Este trágico episódio demonstra a face mais violenta e amargamente irônica da política de identidade, quando anfitriões vulneráveis fingem ser refugiados para garantir sua sobrevivência econômica e justificar sua migração com o apoio do regime de assistência internacional. Após esse episódio, as estradas de Akkar foram bloqueadas em sinal de protesto e solidariedade.

\section{Humanitarismo compensatório: um habitat em mudança}

O tipo de ONGs que apoiavam famílias locais dispostas a hospedar refugiados sírios foi um fator determinante na avaliação de sua reputação na sociedade local, também nos grupos de refugiados sírios. Por exemplo, Najwa, uma libanesa moradora da aldeia de Bebnin (Akkar), disse sobre seus vizinhos: "Eu não confio neles. Eu sei que eles recebem dinheiro de uma associação saudita para hospedar

14 de janeiro de 2013.

Al-Bahsa, 12 de fevereiro de 2013.

8 Isso pode ser encontrado online em http://english.al-akhbar.com/content/escape-hell-lebaneseamong-victims-migrant-boat-disaster (último acesso: 9 de fevereiro de 2021). Turcomenos e beduínos também fingiram ser sírios para obter lucros. 
uma família síria. Eles se tornaram corruptos como seus financiadores." Outra família local foi vista como oportunista por mudar sua visão política para lucrar com o financiamento humanitário: "Aqueles que hospedam refugiados não o fazem por motivos humanos. Eles querem enriquecer tirando dinheiro de países que não deveriam estar aqui", comentou Lama, ${ }^{9}$ uma libanesa moradora da cidade de Halba (Akkar) que falava sobre seu vizinho ser financiado por uma organização do Kuwait para hospedar duas famílias de refugiados sírios.

A hospitalidade financiada para refugiados se tornou uma oportunidade econômica para as famílias locais. Simultaneamente, a população local de outras partes do Líbano com quem me encontrei ao longo dos anos acreditava que esta região libanesa era "rude" e consistia em camponeses sem educação com uma identidade inerentemente negativa. Com o incentivo humanitário da hospitalidade local, as pessoas de Akkar foram frequentemente acusadas de aproveitarem o deslocamento de pessoas da Síria para aumentar os preços das moradias, explorar a força de trabalho barata e revelar seu racismo contra os sírios em vingança pela opressão histórica síria.

A família de Osama na aldeia de Bebnin (Akkar) ${ }^{10}$ hospedou uma família síria da Duma sem receber nenhum dinheiro de ONGs ao longo de 2012. Eles estavam bem conectados com o mukhtar local - oficial do estado - que intercedeu e solicitou que uma ONG internacional os selecionassem para receber apoio financeiro. $\mathrm{O}$ vizinho de Osama também acomodou uma família síria sem pedir que pagassem aluguel, mas quando viram que a família de Osama recebia apoio financeiro, decidiram não continuar oferecendo sua hospitalidade. De acordo com Osama, a situação financeira de seu vizinho não mudou, mas eles esperavam que uma ONG internacional os financiassem quando viram que Osama estava recebendo ajuda. Esta anedota demonstra como a política humanitária comercializou um valor cultural como a hospitalidade. Assim, a hospitalidade passou a ser o vetor de julgamentos macroéticos externos e êmicos; os habitantes locais eram vistos como gananciosos ou generosos, embora a ganância não exclua necessariamente a mágoa, pois, às vezes, é um de seus sintomas.

Revolvendo o discurso político oficial em torno dos refugiados sírios como um "problema existencial para o Líbano","11 de uma perspectiva humanitária internacional, o fato de os hóspedes refugiados terem superado o período de acolhimento foi compensado pelos serviços e ajuda prestada às comunidades locais e pelo aumento da renda de segmentos oligárquicos ricos e politicamente influentes da sociedade de Akkar que poderiam se beneficiar da presença local sem precedentes de refugiados e atores humanitários.

914 de janeiro de 2013.

1014 de janeiro de 2013.

${ }^{11}$ Embaixador do Líbano nos Estados Unidos, Antoine Chedid, no Wilson Center em Washington DC, 29 de outubro de 2013. http://www.wilsoncenter.org/event/humanitarian-crisis-impact-syrianrefugees-lebanon. Último acesso: 27 de maio de 2021. 
No início de 2013, os profissionais das ONGs notaram a deterioração no relacionamento entre a população local e os refugiados sírios. O sentimento local de estar sobrecarregado com o que se tornou um deslocamento de longo prazo estava associado à crença enganosa de que os refugiados recém-chegados constituíam a principal fonte de risco econômico, político e de segurança. Conforme afirmado por Walid, um residente de Halba: "Costumava ter empatia - ta'atuwf - com os sírios, mas agora ela desapareceu. Você pode sentir a tensão agora. Não estou surpreso: depois de hospedá-los até somos roubados por eles."12 A ONG libanesa ALEF (2013) relatou que as pessoas em Kab Elias (Vale do Beqaa) nomearam os campos não oficiais onde os sírios estavam se reassentando de musta'amarat - como os palestinos geralmente chamam de assentamentos israelenses - expressando, portanto, altos níveis de não aceitação.

Algumas pessoas locais que se referiram ao ato de compartilhar espaços e recursos com os sírios em termos de hospitalidade (diyafa) usaram o pertencimento religioso como forma de expressar distância emocional da crise síria, por exemplo, retratar a hospitalidade oferecida aos refugiados como "uma coisa muçulmana". Noha, um morador libanês cristão, sugeriu que a maioria dos refugiados sírios tendiam a mudar-se para as aldeias muçulmanas ao redor de Qobayat porque as autoridades locais das aldeias de maioria cristã os rejeitavam. Com esta declaração, Noha ${ }^{13}$ se referiu à sua própria comunidade confessional para se desligar do influxo de refugiados e da gestão regional do mesmo. Nawal, ${ }^{14}$ uma libanesa de Halba, também revelou a necessidade de separar sua vida da presença de refugiados sírios, mas ela contraditoriamente expressou proximidade emocional e identificação com a situação síria ao afirmar: "Eu nunca os hospedaria. Eu não quero mais machucar minha mente".

O humanitarismo internacional interferiu ao desconsiderar as capacidades locais para lidar e manter a estabilidade, ignorando as experiências comuns que uniam os moradores locais, refugiados e migrantes da região de Akkar. Como alternativa, as agências humanitárias capitalizaram o que costumava dividir os habitantes e, nos estágios iniciais, desenvolveram seus programas com base nisso. A ajuda foi inicialmente fornecida de acordo com supostas divisões sociais, como os sírios não tendo que lidar com os libaneses como se nunca tivessem se conhecido antes, em vez de se concentrar nos fatores de conexão. Nesse contexto, iniciativas como aquelas da ONG Refugiados $=$ Parceiros (Refugees=Partners) que trabalharam nas demografias do Líbano e da Síria contra os estereótipos e a violação dos direitos dos refugiados sírios no Líbano foram esquecidas.

A experiência dos refugiados sírios em Akkar lembrou o setor de desenvolvimento e ajuda de como são terríveis as necessidades locais. Também

\footnotetext{
12 Halba, 5 de outubro de 2012.

1311 de novembro de 2012.

1411 de novembro de 2012.
} 
destacou que as necessidades locais não estão apenas associadas a "crises de refugiados" e que as solicitações locais precisam ser atendidas individualmente. Os programas humanitários inclusivos de hoje ainda são projetados em modelos nascidos em tempos de emergência em locais onde os anfitriões locais também são considerados vulneráveis. Em 2017, profissionais humanitários locais que participaram de atividades geradoras de renda explicaram-me que esses modelos costumam ser definidos de acordo com as características das condições dos refugiados. Por um lado, o humanitarismo de longo prazo não parece mais ser sobre guerra e pessoas em movimento forçado, uma vez que abrange grandes períodos de tempo. Por outro lado, o humanitarismo compensatório estabelece programas para todos; no entanto, às vezes não consegue atrair a atenção local.

No geral, a experiência dos refugiados sírios no Líbano proporcionou a oportunidade de formular e atender aos direitos e necessidades locais, indo muito além dos programas de assistência inclusivos que foram implementados por causa da chegada de refugiados sírios. No caso de uma área historicamente negligenciada que nenhuma política compensatória pode jamais pagar, a hospitalidade se tornou a construção epistêmica de um ambiente onde os locais esperavam para ver suas necessidades legitimadas, reconhecidas e satisfeitas.

Nada, uma mulher libanesa de Wadi Khaled (Akkar) - um conjunto de aldeias extremamente perto da fronteira com a Síria - mostrou-me seu novo aquecedor em uma noite extremamente fria de dezembro de 2012, mas ela não estava feliz por finalmente ter recebido um pela primeira vez em sua vida: "Recebi porque estou hospedando uma família síria. Quero dizer, isso ainda é difícil de aceitar." Assim, a presença de refugiados sírios se tornou a condição necessária para alguns libaneses se tornarem cidadãos de fato e beneficiários de assistência humanitária. Da mesma forma, Dima, ${ }^{15}$ de Halba, lembrou amargamente que não tinha provisão de serviços básicos na região antes da chegada dos sírios: "Não tinha ninguém antes. Precisávamos dos sírios para merecer eletricidade e estradas pavimentadas?"

Na verdade, o humanitarismo compensatório não pode curar velhas feridas.

\section{Uma taxonomia das necessidades etnocêntricas}

Em março de 2016, Amal me ligou; ela ficou alarmada por não conseguir sacar dinheiro usando seu cartão de racionamento eletrônico de um caixa eletrônico local em Halba. Ela havia sido cancelada dos registros do United Nations High Commissioner for Refugees (UNHCR) como uma refugiada síria no Líbano? Falei com meus contatos humanitários em Beirute para acessar rapidamente seu dossiê do UNHCR. Embora eu não tenha tido sucesso, ela logo descobriu por meio do contato local do UNHCR que pensaram que ela e sua família teriam retornado para a Síria.

1510 de agosto de 2012 . 
Desde 2011, a elegibilidade dos refugiados sírios para ter acesso à assistência internacional não tem sido um processo único: o registro e o cancelamento do registro são recorrentes, revelando a natureza pontuada do humanitarismo internacional (Feldman, 2018). Esta "política de policiamento de categorias" (Feldman, 2012, p.394) assume que os beneficiários se enquadram em categorias específicas para se qualificarem para bens e serviços, convencendo as pessoas de que suas necessidades devem ser apresentadas e executadas como etnizáveis. Ou seja, como pertencentes à sua comunidade e distintos de outros grupos sociais, e que a proteção e a assistência só podem ser asseguradas por sua identidade normativa - a identidade com a qual são aceitos no regime de assistência.

Como mais uma evidência da vacilante política de identidade do humanitarismo, a United Nations Relief and Works Agency for Palestine Refugees in the Near East (UNRWA) do Líbano contou 29.000 refugiados da Síria no final de dezembro de 2019. Entre eles, moradores de campos palestinos, especialmente do campo de Yarmouk, que foi destruído por confrontos entre as milícias que se opunham e as que apoiavam o regime de Bashar al-Asad. Como os serviços para os palestinos são normalmente cobertos pelo mandato da UNRWA, inicialmente algumas ONGs negaram ajuda a esses refugiados.

De acordo com profissionais humanitários internacionais, no entanto, a partir de 2013, as organizações que geralmente não trabalhavam com os palestinos - por exemplo, o Danish Refugee Council (DRC) - gradualmente adaptaram suas políticas para se tornarem mais flexíveis e desfocar as linhas das categorias de refugiados. Algumas ONGs internacionais temporariamente adotaram medidas excepcionais para tratar de casos ad hoc de palestinos da Síria. Mas, as organizações lideradas por refugiados sírios que entrevistei em 2017 em Trípoli (cidade no norte do Líbano) e na capital Beirute, como Lamset Ward e a rede Tamas, afirmaram que mantiveram seus critérios de elegibilidade flexíveis durante as chegadas dos refugiados sírios no Líbano. Neste contexto, Hala, uma palestina do campo de Yarmouk da Síria que se mudou para al-'Abdeh em Akkar, afirmou que seus pedidos de ajuda foram rejeitados por algumas ONGs internacionais e pelo UNHCR depois que ela cruzou a fronteira com o Líbano. Assim, ela se tornou uma refugiada de segundo grau: ${ }^{16}$

Sempre vivi como qualquer outra cidadã síria em Baramke [bairro de Damasco] e agora sou tratada como se minha identidade (hawiye) não valesse um único centavo. Fui bombardeada como todos os outros cidadãos sírios. Também perdi meu emprego e meu amado por causa do conflito. Quantas vezes na minha vida tenho que ser refugiada?

"Refugiados sobrepostos" (Fiddian-Qasmiyeh, 2011), como os palestinos da Síria, desafiam a lógica humanitária comum de atribuir uma identidade de vítima única aos destinatários da ajuda. Além disso, atritos dentro do grupo muitas vezes ocorrem como resultado das decisões de governança taxonômica, uma vez que

$\overline{16} 7$ de janeiro de 2013 . 
todos os refugiados carregam uma carga diversificada e sofrem de diferentes graus de abandono social como resultado da experiência de guerra e condições de privação.

De acordo com os destinatários da ajuda em Akkar, o sistema humanitário ignorou essa diversidade experiencial. O "trauma da mudança de categoria" (Feldman, 2012) gerou muitos desses atritos dentro do grupo e foi ativado por mudanças abruptas na distribuição de ajuda e na seleção de beneficiários. Por exemplo, o World Food Program (WFP), depois de garantir o fornecimento incondicional de alimentos aos primeiros refugiados sírios que fugiam para o Líbano, optou por cortar suas despesas encurtando sua lista de beneficiários. O valor dos vouchers usados para comprar alimentos em lojas de varejo locais, devido a déficits orçamentários, variou de 46.000 Lira libanesa por mês a 35.000 Lira libanesa por ano, além do WFP ${ }^{17}$ excluir alguns beneficiários anteriores de assistência futura. ${ }^{18}$

Essa mudança de política causou muito ressentimento entre os refugiados e levantou suspeitas sobre a forma como foram selecionados. Eu ouvi comentários ácidos e amargos de sírios sobre palestinos da Síria e sobre outros sírios. A maioria dos refugiados apontaria a wasta (rede de conexões pessoais) como a única maneira possível de preservar a elegibilidade e o acesso à assistência, enquanto eles queriam se livrar da mudança contínua das categoria burocráticas para acessar os serviços. Uma vez, quando visitei a barraca de Amina em al-Bahsa, ela estava chorando. Naquele ano, sua família não recebeu diesel (mazut) para o inverno. Amina se desesperou com a "perda de reconhecimento" (Feldman, 2012); um reconhecimento de que, como síria, tinha permitido que ela fosse uma refugiada de "primeiro grau". Ela disse que o UNHCR foi um ator que promoveu a desigualdade: ${ }^{19}$

A ONU me disse que mudou sua política. Estamos aqui há três anos e agora eles precisam priorizar os recém-chegados. Eles trataram de nossas terríveis condições? Recebemos ajuda para mudar alguma coisa? Estamos condenados a morrer de frio este ano? Até os palestinos receberam diesel. Eu vi uma mulher palestina que era minha vizinha em Homs [cidade da Síria], e ela estava carregando diesel. Eu perguntei a ela se a ONU tinha dado a ela e ela acenou com a cabeça e zombou de mim. Estou farta de ser humilhada.

Esses efeitos da etnização das necessidades e dos serviços eram normalmente rejeitados pela maioria dos profissionais humanitários que entrevistei em Akkar. Em vez disso, as tensões locais foram explicadas como problemas estruturais pré-existentes, lembrando-me do trabalho de Ferguson (1994) em Lesoto, culpando a ignorância da população local ou a falta de infraestrutura doméstica. Entrevistas com profissionais locais que trabalham para ONGs internacionais ou ONGs locais

\footnotetext{
17 A mudança de política ocorreu porque o WFP declarou que seus critérios de elegibilidade para assistência não poderiam ser estabelecidos antes usando métodos racionais e previsíveis. Portanto, a agência inicialmente optou pela distribuição aleatória.

${ }^{18} \mathrm{O}$ UNHCR cancelou automaticamente o registro de refugiados que não vão aos centros de distribuição de alimentos por três meses consecutivos. Na primeira semana de novembro de 2013, 13.000 sírios foram cancelados no Líbano por esse motivo.

1914 de dezembro de 2012.
} 
foram particularmente perspicazes em relação à articulação das deficiências locais como a causa das falhas do projeto. Por exemplo, um profissional libanês que trabalha para a Fundação do Qatar em Trípoli falou sobre o número crescente de programas dirigidos a libaneses e sírios: ${ }^{20}$

A integração social entre as duas populações sempre existiu, apesar das políticas regionais. Não tem necessidade de projetos específicos para reduzir o ressentimento mútuo. Agências humanitárias ocidentais usam a narrativa das tensões sírio-libanesas para limpar sua imagem depois de terem causado tantos danos.

Embora eu tenha entrevistado principalmente profissionais de ONGs internacionais em Akkar, percebi que a etnização das necessidades não era sua prerrogativa. De acordo com os professionais de uma ONG libanesa, ${ }^{21}$ eles explicitamente etnicizaram os beneficiários da ajuda por razões logísticas e para cumprir a agenda dos doadores estrangeiros: "Temos uma agenda diferente para refugiados iraquianos, sírios e palestinos. Lidamos com todos eles separadamente, pois é mais fácil fazer as coisas dessa maneira." A resposta social a essa tendência interfere nas percepções e nos relacionamentos mútuos. Como Ahmed, ${ }^{22}$ um palestino do campo de Yarmouk da Síria, afirmou: "Só posso obter ajuda da UNRWA. Se eu não fosse palestino, teria centenas de ONGs nas quais posso contar. Eles têm muito cuidado para não confundir um palestino com um sírio." Assim, os beneficiários têm de sobreviver dentro de espaços pré-estabelecidos, onde sua posição na pirâmide taxonômica da ajuda garante ou nega serviços e suporte.

Como outro exemplo, os profissionais do Norwegian Refugee Council (NRC) ${ }^{23}$ disseram que dividiram seu orçamento em programas de educação para moradores de campos palestinos e sírios que aderiram ao programa Back to School, que abriu aulas para crianças sírias em escolas públicas libanesas em Baalbek e Zahle (Vale do Beqaa). Quando os palestinos da Síria chegaram, eles foram incluídos automaticamente nos programas para os palestinos sem qualquer consulta, de acordo com um membro da equipe do NRC. Essa decisão, portanto, negligenciou sua possível identificação com sírios, em vez de palestinos do Líbano. Na mesma linha, Khaled, um refugiado do Sudão que conheci em al-'Abdeh, expressou claramente sua crença em fazer parte de uma taxonomia moral de necessidades básicas, que não levou em consideração a temporalidade da condição de refugiado nem promulgou um sistema justo: ${ }^{24}$

O estado libanês nem mesmo satisfaz as necessidades de seus próprios cidadãos. Mas, tem uma hierarquia cruel no Líbano: os libaneses vêm primeiro, depois os palestinos e, finalmente, os iraquianos e os sudaneses. Nenhuma ajuda vem para nós, embora estejamos aqui há mais tempo do que os outros.

\footnotetext{
2018 de dezembro de 2012.

${ }^{21}$ Halba, 17 de outubro de 2012.

22 Al-'Abdeh, 12 de janeiro de 2012.

${ }^{23}$ Beirute, 15 de janeiro de 2012.

${ }^{24} 4$ de janeiro de 2013.
} 
A nacionalidade não é primordial, mas sim uma construção adequada à era moderna (Calhoun, 1993). No entanto, o caráter fictício e vazio da etnia às vezes era reconhecido, mas aceito pelos humanitários, afirmando que a etnização da ajuda era inevitável, pois era simplesmente um reflexo da sociedade libanesa, que eles não pretendiam mudar com seu trabalho. Avaliar até que ponto a programação humanitária alimentou a etnização das necessidades e dos serviços locais ou se inscreveu nas clivagens pré-existentes continua sendo uma questão complexamente inter-relacionada. Meu empenho aqui foi entender como as pessoas assistidas responderam a tais programas e como conectaram a logística humanitária à política de identidade local.

\section{Conclusão: para uma neo-etnização das ajudas humanitárias?}

Com baseem práticas comuns, as redes sociais nasaldeias de Akkar foram capazes de trazer à luz uma configuração de identidade de pertencimento desvinculada de etnia e religião. Isso ocorreu especificamente no norte do Líbano, onde refugiados sírios trabalhavam como migrantes não qualificados antes da insurreição de 2011. ${ }^{25}$ Um bom exemplo disso foi a prática cotidiana de compartilhamento de carros que testemunhei em al-Bahsa (oeste de Akkar). O compartilhamento de carros era uma prática relativamente comum entre os moradores sírios e libaneses da região de Akkar, pois eram mal servidos por transporte público. Muitas famílias sírias e libanesas de baixa renda não tinham dinheiro para ter seu próprio carro. No entanto, durante minhas estadias prolongadas, tomei conhecimento de famílias sírias e libanesas que compraram carros usados e dividiram os custos de uso e manutenção ou mesmo dividiram os custos de compra. Tais práticas coletivas contradizem a narrativa predominante de tensões intergrupais e são sinais de mecanismos de autossuficiência preexistentes. Esses arranjos de subsistência mútua visavam apoiar famílias múltiplas além de sua identidade nacional predefinida.

O pertencimento a um grupo pré-definido não conseguiu captar táticas distintas de sobrevivência, que, neste caso, formaram uma ampla rede de apoio mútuo e negociação. Neste quadro, a abordagem baseada na prática é um instrumento poderoso para revelar como a filiação social e o status econômico não são definidos nacionalmente, em linha com o movimento acadêmico do determinismo estrutural da delimitação em direção a uma ênfase na agência (Wimmer, 2008).

Embora a busca e gestão de recursos seja geralmente mais difícil para os refugiados (visto que eles normalmente têm conexões e redes mais fracas para construir, ao contrário dos locais), os refugiados sírios e cidadãos libaneses economicamente vulneráveis enfrentam os mesmos custos de vida e, em alguns

\footnotetext{
${ }^{25}$ Os oponentes sírios saíram às ruas para protestar contra o regime sírio desde março de 2011. Com a repressão estatal e o subsequente armamento da oposição síria, o levante gradualmente se transformou em um conflito em grande escala.
} 
casos, recebem quase o mesmo salário. Manar ${ }^{26}$ é um morador de Halba (capital de Akkar) cujo marido trabalhava em uma fábrica em Beirute por 450 dolares por mês, metade dos quais eram gastos em seu trajeto diário. Ela costumava ajudar crianças refugiadas sírias com seus deveres de casa à tarde gratuitamente, enquanto a família das crianças pagava a ela um aluguel mensal pelo terreno onde construíram sua barraca, escolhendo seu terreno em vez de outros oferecidos a eles. Da mesma forma, testemunhei suporte mútuo frequente e trocas de serviço entre refugiados e moradores locais. Isso demonstra a importância de desenvolver uma compreensão mais profunda de como as identidades se confundem por meio de práticas compartilhadas. Evitar a linguagem de valores e normas orientados para a cultura permite o agrupamento de pessoas com base no que elas realmente fazem, e não em quem elas supostamente são e como se sentem no ambiente anfitrião.

Transcendendo as categorias de fronteira ao observar práticas socioeconômicas comuns ou diferentes, esses grupos definidos por práticas emergentes se relacionam aos contextos mais amplos como grupos coletivos (Warde, 2014) em vez de categorias classificadas por nacionalidade. Isso confronta a demografia dominante do sistema humanitário. A abordagem das práticas e seu desenvolvimento histórico pode revelar associações sociais reais, mas os refugiados ainda precisam responder aos critérios padronizados de elegibilidade, agitando suas bandeiras de identidade para se qualificar para alimentação, saúde, serviços de educação, reassentamento ou mesmo o direito de se mudar. A abordagem baseada na prática cria espaço para redefinir uma epistemologia mais autêntica de necessidades e regimes de assistência.

Em fevereiro e março de 2017, participei de um curso de treinamento em fabricação de chocolate financiado pela União Européia e pela UNICEF por quatro semanas. Fazer chocolate se tornou uma história de sucesso na diáspora de refugiados sírios, e o lema desse sucesso empresarial se tornou conhecido como "paz pelo chocolate" ${ }^{27} \mathrm{O}$ workshop ocorreu em Halba duas vezes por semana durante três meses e foi administrado pela ONG local Akkar Network for Development (AND), ${ }^{28}$ que administra vários programas de subsistência na região de Akkar em parceria com as ONGs internacionais. De acordo com os trabalhadores humanitários, ${ }^{29} \mathrm{a}$ fabricação de chocolate não foi uma proposta baseada em uma análise de lacunas de competências do mercado, mas foi criada de acordo com os recursos disponíveis. Entre os nove estagiários, havia seis mulheres sírias e três libanesas cujas despesas

\footnotetext{
${ }^{26}$ Halba, 27 de fevereiro de 2017.

${ }^{27}$ Sweet Success: How the Haddads went from Refugees to Employers in 1 Year," CBC News, 7 de janeiro de 2017.

${ }^{28}$ Durante minha entrevista, o UN Development Program dizeu que tinha instalado uma fábrica de chocolate em Akkar, mas grandes segmentos de residentes locais, e até mesmo trabalhadores humanitários, não sabiam do curso nem onde a fábrica estava localizada. Halba, 28 de fevereiro de 2017.

${ }^{29}$ Halba, 24 de fevereiro e 6 de março de 2017.
} 
de transporte foram cobertas pela filial da AND e que sofriam de vulnerabilidades econômicas muito semelhantes.

Como investiguei anteriormente (Carpi, 2020a), a tentativa humanitária de produzir chocolate para gerar renda não visava principalmente à autossuficiência dos refugiados. O objetivo era explicitamente aumentar a participação de cidadãos e refugiados nos mercados locais para promover a coesão social e evitar tensões. A socialização entre as mulheres libanesas e sírias, naquele contexto específico, não aconteceu de fato, pois continuei encontrando as estagiárias fora do programa. No entanto, isso não significa que a socialização nunca ocorreu entre os sírios e libaneses em geral, especialmente no caso de pessoas de origens beduínas que tendem a minimizar sua pertença a um estado-nação e se concentram nas continuidades da vida beduína através das fronteiras regionais.

Em contraste, em minhas conversas com profissionais humanitários que trabalham com coesão social, a falta de interação social - especialmente entre jovens e crianças - durante ou após um programa foi considerada um fracasso pelos doadores que ajudam financeiramente os projetos humanitários, como se as sociedades locais fossem exclusivamente moldadas por e funcionando por causa da programação humanitária. Aqui, a questão mais importante é que, apesar da matriz intergrupal, este programa de subsistência humanitária foi incapaz de capturar formas mais articuladas e combinadas de filiação social que derivavam de práticas comuns e apoio mútuo, embora dentro de economias hierárquicas e desiguais. Uma abordagem etnocêntrica, portanto, ignora as associações sociais definidas pela prática e trata a coesão social e a estabilidade como baseadas na identidade. Tendo trabalhado no mapeamento local dos programas de subsistência em Akkar ao longo de 2016 e 2017, nenhum desses capturou tais arranjos pré-existentes para a sobrevivência econômica, mas abordou diferentes grupos nacionais como entidades separadas que precisavam se encontrar e se reconciliar.

O caráter etnocrático da programação humanitária leva à negligência persistente das práticas intergrupais pré-existentes, e não é exclusivo da ação humanitária no Oriente Médio. Ao longo do tempo, percebi que o número de ONGs internacionais que implementaram projetos de forma consistente para diferentes grupos nacionais era muito maior do que nos anos anteriores. Em minhas conversas com trabalhadores de ONGs internacionais, a principal preocupação era a coesão social para permitir a estabilidade local. Por exemplo, programas de vários grupos foram discutidos como se tivessem o objetivo de gerar o primeiro encontro entre libaneses, palestinos e sírios; notavelmente, grupos demográficos que há muito compartilham espaço e recursos na região e em outros lugares.

Por mais que o Oriente Médio seja frequentemente excepcionalizado na mídia e relatos acadêmicos, as abordagens etnocráticas humanitárias não se limitam à região. Por exemplo, um profissional da International Committee of the Red Cross no Nepal comentou que era mais difícil realizar reuniões comunitárias nas cidades 
porque normalmente acontecem com várias comunidades ao mesmo tempo. Essa crença sugere que uma "criação estrategicamente gerenciada de um espaço neutro" é necessária, ao invés de reconhecer e construir sobre a natureza multi-grupo de tais reuniões em ambientes urbanos (British Red Cross, 2012, p. 35).

A tendência atual de incluir diferentes grupos nacionais em um único programa humanitário se reflete nos esforços coletivos governamentais, não governamentais e do setor privado, juntamente com a abordagem de New Way of Working (NWOW) do UN Office for the Coordination of Humanitarian Affairs (OCHA), que foi apresentado no âmbito dos United Nations Sustainable Development Goals para 2030 e institucionalizados no World Humanitarian Summit de 2016. Esta abordagem gira em torno do reforço, ao invés da substituição, de capacidades contextuais pré-existentes e redes de suporte. O número de programas projetados para sírios, palestinos e libaneses ao todo, como confirmou um oficial de proteção do UNHCR, ${ }^{30}$ agora é muito maior do que antes de 2016. No entanto, muitos projetos intergrupais continuam a ser promovidos em retórica pública e campanhas formais, em vez de efetivamente praticados (Carpi e Diana, 2019, p. 145).

Entre 2015 e 2016, Chiara Diana e eu examinamos criticamente a intervenção da ONG Right to Play (RtP), fundada pelo Canadá, em crianças locais e refugiadas em al-Qobbeh, um bairro desfavorecido em Trípoli no norte do Líbano. A RtP trabalha com crianças refugiadas palestinas no Líbano desde 2006 e investiga o impacto da guerra síria nas crianças refugiadas e nas comunidades locais desde 2013. Esta ONG internacional atualmente coordena atividades lúdicas e esportivas para crianças libanesas e sírias na província de Trípoli. O objetivo da RtP é encorajar crianças e jovens a se misturarem com seus colegas, a se engajarem socialmente e a se absterem de ingressar em grupos armados ou qualquer outra forma de violência política.

As atividades lúdicas que originalmente envolviam crianças de diferentes origens nacionais separadamente, e que mais tarde se tornaram inclusivas para desencadear coesão e estabilidade, contribuíram para moldar a subjetividade social das crianças com base em suas nacionalidades, em vez de em torno das circunstâncias políticas e sociais em que vivem. Eles foram originalmente configurados em termos de nacionalidade, como observamos nos parques infantis, mas as atividades lúdicas de hoje, muito frequentemente, ainda se desenvolvem como atividades intergrupais apenas em um nível ideal (Carpi e Diana, 2019, p. 145).

Tais preocupações com a coesão social emergem claramente na reformulação de programas que visam ser inclusivos nacionalmente, sendo este último usado como uma estratégia para aliviar tensões que supostamente acontecem em contextos nacionalmente mistos. Nesse sentido, com a abordagem multigrupo atual, algumas necessidades e serviços são atendidos por meio de uma abordagem baseada na

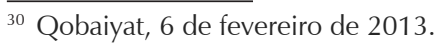


área e, portanto, são definidos pela geografia e não pela política de identidade. A priorização de programas de coesão social em áreas demograficamente híbridas é problematicamente baseada em medidas preventivas de segurança, revelando assim uma etnização duradoura das ajudas. Com base nos meus estudos, tento portanto construir uma compreensão "pós-étnica" das necessidades humanas e da prestação de serviços, especialmente em contextos em que as políticas de identidade garantem o impedem o acesso das pessoas aos regimes de assistência.

\section{Referências bibliográficas}

ALEF-Act for Human Rights. Two Years On: Syrian Refugees in Lebanon. Beirut: IKV Pax Christi, 2013.

BAHRAM, Haqqi. Kurdish Guests or Syrian Refugees? Identity, Belonging and IntraEthnic Displacement. Routed Magazine, Oxford Migration Conference paper. May 29, 2020. Disponível em: < https://www.routedmagazine.com/omc2020-1-kurdishguests-syrian-ref $>$. Acesso em: 25.05.2021.

BRITISH RED CROSS. Learning from the City. British Red Cross Urban Learning Project Scoping Study. London: British Red Cross, 2012.

BRUN, Cathrine. Hospitality: Becoming 'IDPs' and 'Hosts' in Protracted Displacement. Journal of Refugee Studies, v. 23, n. 3, p. 337-355, 2010.

CALHOUN, Craig. Nationalism and Civil Society: Democracy, Diversity, and SelfDetermination. International Sociology, v. 8, n. 4, p. 387-411, 1993.

CARPI, Estella. Specchi Scomodi. Etnografia delle Migrazioni Forzate nel Libano Contemporaneo. Milan: Mimesis [Italian], 2018.

CARPI, Estella. Towards a Neo-Cosmetic Humanitarianism. Refugee Self-Reliance as a Social Cohesion Regime in Lebanon's Halba. Journal of Refugee Studies, v. 33, n. 1, p. 224-244, 2020a.

CARPI, Estella. The Borderwork of Humanitarianism During Displacement from WarTorn Syria. Livelihoods as Identity Politics in Northern Lebanon and Southeast Turkey. In: BABAR, Zahra (ed.). Mobility and Forced Displacement in the Middle East, p. 3353. London: Hurst and Oxford University Press, 2020b.

CARPI, Estella; SENOGUZ, Pinar. Refugee Hospitality in Lebanon and Turkey. On Making the Other. Journal of International Migration, 2018.

CARPI, Estella, DIANA, Chiara. The Right to Play versus the Right to War? Vulnerable Childhood in Lebanon's NGOization. In: CHENEY, Kristen; SINERVO, Aviva (eds). Disadvantaged Childhoods and Humanitarian Intervention: Processes of Affective Commodification and Objectification, p. 135-156. New York: Palgrave, 2019.

CHALCRAFT, John. The Invisible Cage: Syrian Migrant Workers in Lebanon. Stanford, CA: Stanford University Press, 2009.

FELDMAN, Ilana. The Challenge of Categories: UNRWA and the Definition of a Palestine Refugee. Journal of Refugee Studies, v. 25, n. 3, p. 387-406, 2012.

FELDMAN, Ilana. Life Lived in Relief. Humanitarian Predicaments and Palestinian Refugee Politics. Oakland, CA: University of California Press, 2018. 
FERGUSON, James. The Anti-politics Machine. Development, Depoliticization, and Bureaucratic Power in Lesotho. Minneapolis: University of Minnesota Press, 1994.

FIDDIAN-QASMIYEH, Elena. Invisible Refugees and/or Overlapping Refugeedom? Protecting Sahrawis and Palestinians Displaced by the 2011 Libyan Uprising. International Journal of Refugee Law, v. 24, n. 2, p. 263-293, 2011.

FIDDIAN-QASMIYEH, Elena; QASMIYEH, Yousif M. Refugee Neighbours and Hostipitality. The Critique. January 5, 2017. Disponível em: http://www.thecritique. com/articles/refugee-neighbours-hostipitality-2/. Acesso em: 25.05.2021.

LEBUHN, Henrik. Local Border Practices and Urban Citizenship in Europe: Exploring Urban Borderlands. City, v. 17, n. 1, p. 37-51, 2013.

PITT-RIVERS, Julian. The Law of Hospitality. Journal of Ethnographic Theory, v. 2, n. 1, p. 501-517, 2012.

ROSELLO, Mireille. Postcolonial Hospitality. The Immigrant as Guest. Stanford (CA): Stanford University Press, 2002.

SHRYOCK, Andrew. The New Jordanian Hospitality: House, Host, and Guest in the Culture of Public Display. Society for Comparative Study of Society and History, v. 46, n. 10, p. 35-62, 2004.

SMITH, Anthony D. The Ethnic Revival in the Modern World. Cambridge: Cambridge University Press, 1981.

WARDE, Alan. After Taste: Culture, Consumption, and Theories of Practice, Journal of Consumer Culture, v. 14, n. 3, p. 279-303, 2014.

WIMMER, Andreas. Elementary Strategies of Ethnic Boundary Making. Journal of Ethnic and Racial Studies, v. 31, n. 6, p. 1025-1055, 2008. 